\title{
The dynamical view of natural form
}

\author{
T. Irwin \& S. Baxter \\ Centre for the Study of Natural Design, \\ Duncan of Jordanstone College of Art and Design, \\ University of Dundee, Scotland
}

\begin{abstract}
Design is implicated in most of the social and environmental crises confronting us today. This paper argues that in order for designers working within all areas of specialty to design more sustainably and responsibly, they need to fundamentally change the way in which they think about form. A better understanding of natural form and the way in which it comes into being can inform new ways of conceiving form in the designed world. The work of poet and scientist Johann Wolfgang von Goethe (1749-1832) and modern-day physicist and philosopher Henri Bortoft offers new perspectives on the dynamic unity of natural organisms. The emerging field of biomimicry and biomimetics is based upon the study of natural forms and processes found in nature, but has most often given rise to technology-based solutions that do not reflect an understanding of the unity of the phenomena. Such solutions are not sustainable and fall short of their potential for sweeping change because they have been conceived and applied in a limited context within an outdated design paradigm and a reductionist worldview. This paper reviews Goethe's concept of 'whole' organisms and their temporal, iterative and dynamic nature and shows how a shift in perception of form can inform a new design process in which ethics and sustainability are embedded.
\end{abstract}

Keywords: natural form, dynamic form worldview, morphology, biomimicry, design, sustainability, Goethean science, other ways of knowing, holistic thinking.

\section{Introduction}

This paper is based upon the following contentions: 1) we live in a world of form; both natural and man-made 2) design is primarily a form-giving activity 3) design is implicated in most of the social and environmental crises 
confronting us on a global scale 4) one of the root causes of unsustainable design is the fragmented way designers think about form 5) a better understanding of how natural forms come into being and pass out again can inform a more holistic/ecological design process.

Both form and design are fundamental to our existence. Designer Victor Papanek (1927-1999) contended that "All men are designers. All that we do, all the time is design, for design is basic to all human activity...[it] is the primary underlying matrix of life" (Papanek [1]). If design is the underlying matrix of life, then surely form-giving is the underlying matrix of design. Form-both natural and man-made - is everywhere we look, and is a topic that has concerned philosophers, poets, artists, mathematicians, biologists, physicists and anthropologists for hundreds of years. It would be difficult to find a subject that has spanned so many disciplines. The renowned $20^{\text {th }}$ century biologist Lancelot Law Whyte (1896-1972) writing in 1968, proposed a programme in General Morphology "not only as an appropriate element of basic training in the natural science, but as a way of displaying the unity of many unduly separated academic disciplines. This is a world of form and structure and can only be properly understood as such." (Whyte [2]) Considering how fundamental form is to all areas of design, it is surprising how little attention it is given within most design programmes at the University level. The formal, visual aspects of form may be narrowly addressed at the core level, but deeper considerations connected to the metaphysics, philosophy and biology of form are virtually missing in design education. In this paper we will argue that the morphological view that Whyte referred to, which focuses on organisms as complex, dynamic and temporal 'wholes' that are symbiotically connected to their environment, has the potential to inform a more holistic and responsible design process.

\section{A fragmented view of form}

We are increasingly surrounded by forms of our own making, or what political scientist Herbert Simon termed 'the artificial'; "the world we live in today is much more a man-made, or artificial world than it is a natural world. Almost every element in our environment shows evidence of man's artifice" (Simon [3]). The problem of course, is that our 'artifices' are increasingly threatening the survival of all species of life on the planet.

\subsection{Form, relationship and worldview}

Our contention is that one of the root problems of ill-conceived and unsustainable design is the fundamental way in which designers think about the forms they bring forth. Forms are seen as static and unrelated objects and the faithful, quick and economical realization of their concept is the focus of the design brief. A designer's relationship with a particular form begins with an idea and usually ends either once the concept is approved for implementation, or once the implementation process is concluded. Relationship (between the form and its myriad of context, during manufacture, through use and especially after use) is 
almost never considered an explicit part of the design process or solution. We propose that a shift in focus from objects to relationships must be a criterion for the transition to a new design paradigm.

Such a reassessment of the fundamentals of design philosophy will call for new, more holistic approaches to both problem seeing and problem solving. In his book Paradigm Wars [4], Mark Woodhouse asserts that paradigms are embedded within broader worldviews that influence and direct the various paradigms of which they are comprised. The current design paradigm can be said to exist within the dominant western/mechanistic worldview whose roots can be traced to the scientific revolution of the $17^{\text {th }}$ century (Marshall [5], Capra [6], Korten [7], Roszak [8]). This worldview is characterised by a reductionist approach to understanding natural phenomena (a focus on separate and unrelated parts instead of wholes and relationships), emphasis on quantitative methodologies (only that which is measurable and quantifiable is valid), a belief in a predictable, cause/effect universe (and therefore subject to control) and a conviction in the supremacy of human beings over other species (the natural world is seen as a store of resources for human purposes). Physicist David Bohm argued that the universe is fundamentally 'whole' and that it is our worldview which divides things into separate and unrelated parts: “...wholes is what is real, and...fragmentation is the response of this whole to man's action, guided by illusory perception, which is shaped by fragmentary thought. In other words, it is just because reality is whole that man, with his fragmentary approach, will inevitably be answered with a correspondingly fragmentary response." (Bohm 11]).

Sociologist George Ritzer has termed the imposition of this mechanistic worldview upon society's infrastructure the "McDonaldization of Society" a system designed to deliver "consumers, workers, and managers efficiency, calculability, predictability, and control" (Ritzer [12]). The success of the McDonaldization model is based upon reductionism. All four of its attributes are also found within the traditional design process and can be thought of as The McDonaldization of Design. Designed forms are seen as unrelated, separate, static objects that arise from a process that does not encompass the full cycle of life of a form (conception, implementation, use and end-of-life). And yet as architect and product designer Christopher Williams points out "the world we know is a whole and all its parts respond to the same earthly laws; all substance about us has the same physiochemical basis; all particles of matter are moulded by the same physical laws. The structural unity is the same" (Williams [13]). Ultimately, all form (both natural and man-made) arises out of the nutrient pool of the earth, and must eventually return. Natural forms always arise and return gracefully. Increasingly human-designed forms do so with great resistance and toxic result.

\section{The dynamic view of form}

An alternative/holistic stream of thought that focuses on the unity of living form has existed far longer than the reductionist view of the $17^{\text {th }}$ century and is once 
again coming to the fore. As early as 385 B.C., Plato explored the connection between ideas and form and Aristotle after him saw form as the qualitative and dynamic essence of things. Leonardo da Vinci's interest extended to form in both the natural and artificial realms and form was a central focus of Kant's philosophy (Whyte [14]). The Romantic movement (in art, literature and philosophy) and the organicist tradition (biology, physics and chemistry) both ran counter to the Cartesian paradigm and its reductionist view of form (Capra [15]). Biophysicist Mae Wan Ho contends that a $20^{\text {th }}$ century 'organic revolution' begun by leading thinkers such as Bergson, Whitehead, Haldane and Needham sought to develop a science of the organism that was appropriate to a new understanding of the wholeness of nature, inspired by recent discoveries in the areas of quantum physics, nonlinear mathematics and complexity of ecosystems (Ho [16]).

It is somewhat ironic that these recent discoveries have confirmed the principles advanced by the organicists and which have been fundamental to eastern spiritual traditions for thousands of years. Fritjof Capra noted that "One of the most important insights of the Taoists was the realization that transformation and change are essential features of nature. A passage in the Chuang-tzu shows clearly how the fundamental importance of change was discerned by observing the organic world: 'In the transformation and growth of all things, every bud and feature has its proper form. In this we have their gradual maturing and decay, the constant flow of transformation and change"" (Capra [17]). Bohm, writing on what he called The Implicate Order argued that so called stable structures could not be understood as separate and permanently existent objects but only as forms arising out of the greater flowing movement which would ultimately dissolve back into the same source (Bohm [18]). Both eastern philosophy and physics emphasize two important concepts regarding the origins of form: 1 ) form is flowing movement deriving from a single source (all is one) and 2) form can be seen as a node within a dense web of relationships.

\subsection{Goethe's way of seeing}

What distinguishes the poet and scientist Johann Wolfgang von Goethe (17491832) from other noted students of form was his development and application of what he called a dynamic way of seeing the unity of natural phenomena. This method is based upon a participatory, phenomenological engagement with a natural form, such as a plant in which it is allowed to presence forth on its own terms. Goethe's way of seeing stands in stark contrast to the reductionist science of Isaac Newton (1642-1727), of whom he was highly critical. Goethe spoke of the absent whole and saw the unity of the phenomenon as an emergent property of an encounter with the parts. Physicist and philosopher Henri Bortoft describes Goethe's theory of the relationship between the whole and the parts this way: "The whole emerges simultaneously with the accumulation of the parts, not because it is the sum of the parts, but because it is immanent within them." (Bortoft [19]) This refusal to place the primacy on either parts or whole is based upon an understanding of the dynamic and temporal nature of the absent whole. It can only be understood by imagining the dynamic process of transformation 
over time in one's imagination. One of Goethe's great contributions was to develop a rigorous method that schooled imagination as a scientific tool of cognition.

\subsection{The temporality of 'whole' phenomena}

More than any of his contemporaries, Goethe understood that form is process in time and a living organism is in a constant state of coming into being; "The forms of life are not 'finished works but always forms 'becoming'...the becoming that belongs to this constitution is not a process that finishes when it reaches a certain goal, but a condition of existence-a necessity to change in order to remain the same." (Brady [20]) Therefore in Goethe's view, the 'whole' plant would include its journey from the first shoot emerging from the seed, through development, flowering, fruiting and the plant's eventual demise. Our habitual way of thinking sees the plant as static snapshots in time, frozen in one stage of development or another. What Goethe meant by the absent whole is the entirety of a process that can only be perceived and understood in our imagination; as we imagine the plant's morphological transformation of coming into being and passing out again.

An example used by Goethean scientist to demonstrate the dynamic process of form is to observe the succession of leaves along the stalk of a plant. The leaves at the bottom are significantly different than those along the middle or the top of the stalk; no two leaves have the same shape. Were we to juxtapose three leaves taken from the bottom, middle and top, out of context, we might easily assume they came from different plants. "But however, let the observer work through the series, as Goethe claimed that he did, both forward and backward, until it becomes a continuous movement, and then glance again at the extracted forms. If these can be placed within the context of the movement of the whole series they will not longer seem unlike." [21]

This way of perceiving form is particularly relevant to the design process. In the Goethean method, unity in form is predicated upon an understanding of the dynamic (fluid) absent whole - the temporal entirety of each form's journey from inception to demise. If this understanding and way of thinking about form were integrated into the design process, a designer's task would not only entail conceptualization of a 'final' static form such as a chair or a bridge (often manufactured in a remote process), it would also include the coming into being of the form, its distribution, use, end-of-use and the manner of its demise and return to the nutrient pool (remember Williams' contention that 'given enough time, all form is fluid'). Envisioning every step of the process as dynamic transformation in time would be part of the designer's conceptualization process and his relationship to the form, ongoing. We are not suggesting that a literal and accurate envisioning of every aspect of resource extraction, processing of raw materials and the form's manufacture is possible. However, if designers were responsible for developing a working understanding of the entire lifecycle processes of a form and learned to envision the process as flowing movement as the Goethean method requires, we suggest that many more ethical and 
environmental considerations would come to light than in the current predominantly analytical/intellectual process.

\subsection{Goethean process}

A complete description of Goethean process can be found in (Wahl [22], Hoffmann [23], Holdrege [24], Colquhoun and Ewald [25]) and is not the central focus of this paper. However a brief overview is provided here to illustrate the way in which imagination, intuition and a phenomenological engagement with form are combined with a sensory-based empiricism that is objective in its ability to be replicated and practised as a scientific methodology.

It is important to note that the processes used by Goethean scientists such as Colquhoun, Holdrege and Hoffmann vary slightly from each other and Goethe himself did not break the process down into such distinctive steps. He described a process that combined a 'delicate empiricism' with with intuition and inspiration (the moment of seeing or insight). (Zajonc [26]) The process presented here is a synthesis of processes from the previously mentioned practitioners and the authors' own experience.

\subsubsection{Step one: Exact sense perception}

A detailed sensory-based observation of the phenomenon is undertaken, noting only what can be outwardly perceived by the senses. Judgement and preconceptions are suspended and observation takes place in an open and listening posture. The phenomenon is viewed as if for the first time.

\subsubsection{Step two: Exact sensorial imagination}

What were observed as static, disconnected parts are now brought together and made fluid in the imagination as dynamic process in time. The intention is to experience the unity of the generative process. The imagination is used as a tool of perception to visualize the coming into being of the form and its journey into the future to completion/death. The absent whole is encountered through this process.

\subsubsection{Step three: Encountering the whole}

Active perception and imagining are stilled as one assumes a posture of receptive attentiveness in order to let the phenomenon reveal something of its essential nature. The dynamic transformation envisioned in the previous stage is deepened to reveal the formative gesture of the organism or its life-principles. Such gestures are often realized as sudden insights that disclose the 'whole' phenomenon or the unity that is always present, but never seen.

\subsubsection{Step four: Becoming one with the phenomenon}

In this step, the particular organism studied is transcended and its archetype is encountered. Through intuitive perception we merge with the organism to grasp its inherent meaning or creative potency. In his study of a particular plant, Goethe saw this step as an understanding of the plant archetype that manifests in a multiplicity of forms (species and individual plants), only one of which is the plant being studied. This can be seen as a manifestation of archetypal plant-ness. 
Goethe's method establishes the primacy of the qualitative through the combination of contemplative non-intervention with organic dialectics.

It goes without saying that as a scientific method or holistic way of seeing, Goethean science must be practiced to be fully understood. What can be apprehended from the theory is the way in which it reverses our normal mode of cognition through the employment of our full range of faculties; rigorous sensebased observation and the inner work of schooled imagination and delicately directed intuition. Most designers would acknowledge that both imagination and intuition are inherent in the design process, however Goethean process offers a more rigorous and methodical application of it that can be practiced consistently among a group of people who will usually arrive at similar conclusions. The first step in particular holds promise as a collaborative method of observation of existing design contexts which could serve to enable a multi-disciplinary design team in finding common ground and consensus for problem solving.

\subsection{The holistic mode of consciousness}

In describing Goethe's process, Bortoft contends that our habitual, analytic mode of consciousness is in part a product of our language, in particular our subjectpredicate grammar, "which has the effect of dividing experience into separate elements which are then treated as if they existed independently of each other...the grammatical structure of language articulates the world analytically." (Bortoft [27]) He goes on to describe the holistic mode of consciousness as a complement to the analytical/intellectual mode. By contrast, a holistic mode of thinking is non-linear, simultaneous, intuitive and more concerned with relationships than with the element themselves. This mode of thinking can also be considered a way of seeing "and as such, can only be experienced on its own terms." [28]

Goethean process enables the practitioner to experience relationship as a simultaneous whole within the unity of a form or organism, which Bortoft asserts "amounts to a restructuring of consciousness itself." Unity can only be understood through the active, non-judgemental/phenomenological engagement and participation with a phenomenon. As an example of this dynamical way of thinking and seeing, Bortoft gives the example of a flock of birds in flight. Our habitual, analytic mode of thinking causes us to see the birds as separate entities which are brought together externally in space and sequentially in time so that their movement is experienced only in the abstract. If however, we shift our focus into flying instead of seeing the birds fly, we can "experience this in the mode of dynamical simultaneity as one whole event...it becomes evident...that the description of motion and change as linear sequence of instantaneous states is a device of the intellectual mind"- the result of analytical consciousness [29]. We are, in effect, shifting our attention to sensory experience instead of intellectual analysis, which is similar to the mode of consciousness employed by many schools of meditation in which withdrawing attention from thinking and redirecting it into percepts, reverses the normal learning sequence or process of automatization. When imagination is employed in the Goethean process to see a form coming into being and then the process is reversed, we are in effect deautomatizing our psychological structures and beginning to transform 
consciousness. This, Bortoft maintains was the key to Goethe's way of science and his dynamical way of seeing form. [30]

\section{Biomimicry: A fragmented vs. dynamical view of form}

In her book Biomimicry (1997), Janine Benyus describes a new science that studies nature's models and then imitates or takes inspiration from these designs and processes to solve human problems. More importantly, she goes on to say that the 'rightnesss' of our forms (designs) should be measured by an ecological standard and an approach that views nature as mentor and not as a store of resources for human consumption. (Benyus [31]). Taken in its entirety, this definition is consonant with the dynamic view of form previously described in its focus on the symbiotic webs of relationships among dynamic organisms and their environment (ecology). Any design solution based upon true biomimetic principles would be developed within such a contextual web using sustainable processes for manufacture and the form's eventual return to the nutrient pool would be graceful and non-toxic. Biomimicry applied from within Bortoft's holistic consciousness could not be otherwise.

However biomimicry is often applied in a fragmented way, from within a design paradigm that views forms as separate, static and unrelated objects. Such a fragmented application of a supposed ecological design process cannot yield whole or 'fit' form. For instance Velcro (a two part fastening mechanism comprised of hooks and loops) is often given as the classic example of a biomimetic solution [32] since its design was based upon seed burrs which tenaciously stick to clothing and animal fur. The design was based upon the imitation of one part of the seed burr which only manifests its sticking capacity during a brief stage within its lifecycle. Velcro is often manufactured from unsustainable materials using processes that may or may not be. Re-use or biodegradability is not usually intrinsic to the design, which, we would argue is a fragmented application of biomimetic principles. A 'whole' solution to the same problem would involve the study of the entire lifespan of the organism and an understanding of how it comes seamlessly into being and passes out again without toxic residue or harmful effect. The plant would be studied within the context of its environment in order to understand the dynamics of its ecosystem to provide clues about its fluid transformation into and out of being. Most importantly, it would be studied without preconceptions from a posture of willingness to have the ecosystem disclose principles that might lead to new more appropriate and sustainable solutions. Within such as process, social and environmental sustainability would be implicit.

An example of a solution that embodies the full spectrum of biomimetic principles is The Living Machine, a water purification system developed by John and Nancy Todd. (Todd and Todd [33]) Their design involves pumping grey or toxic waste water through a series of containers or vats, each of which contains a different and diverse system of plants that filter toxins, pollutants, even heavy metals out of the water naturally. The machine transforms liquid waste into drinking water using designed combinations of natural forms. It is largely self- 
sustaining and the design solution is based upon the web of relationships between diverse organisms that are in a constant state of morphological transformation.

These two examples represent only a small step in exploring how a more dynamic way of thinking about form (based upon what Bortoft calls a transformation of consciousness) can lad to a more appropriate and responsible design process. Among the principles suggested by the dynamical view of form are: the ability to see everything (natural and man-made) in a dynamic way, training ourselves to think in longer horizons of time (to imagine the full lifecycles of both natural and artificial forms), to remain open to other ways of knowing, focusing on fluid and symbiotic relationships rather than static objects in space, understanding that forms (both natural and man-made) are inextricably linked to 'place' and therefore holistic design is place-based design and finally, learning to observe from a posture of speculation instead of certainty.

We believe that the Goethean method can be employed within the traditional design process and has the potential to fundamentally shift designers' relationships to nature and ultimately their worldview. It is only from this 'metalevel' that truly sustainable design solutions will emerge.

\section{References}

[1] Papanek, V., Design for the Real World, Academy Chicago Publishers, Chicago, Illinois, pp. 3, 1984.

[2] Whyte, L. L., Aspects of Form, Lund Humphries Publishers, London, pp. X 1968.

[3] Simon, H. A., The Sciences of the Artificial, The MIT Press: Cambridge, Massachusetts and London, England, pp. 4-5, 1969.

[4] Woodhouse, M. B., Paradigm Wars, Frog, Ltd., Berkeley, California, pp. 5-6, 1996.

[5] Marshall, P., Nature's Web, Simon and Schuster, London \& New York, pp. 171-179, 1992.

[6] Capra, F., The Web of Life, Anchor Book/Doubleday, New York, London, pp. 19-24, 1996.

[7] Korten, D. C., The Post-Corporate World, Berrett-Koehler Publishers, Inc., San Francisco, California, pp. 24-28, 1999.

[8] Rosak, T., Where the Wasteland Ends, Celestial Arts, Berkeley, California, pp. 247-254, 1989.

[9] Suzuki, D., Earth Time, Stoddart Publishing, Toronto, Canada, pp. 7-12, 1998.

[10] Bateson, G., Mind and Nature, Fontana Paperbacks, London, pp. 231-232, 1979.

[11] Bohm, D., Wholeness and the Implicate Order, Routledge, London and New York, pp. 7, 1995.

[12] Ritzer, G., Explorations in Social Theory: From Metatheorizing to Rationalization, Sage Publications, Inc., pp. 198-201, 2001. 
[13] Williams, C., The Origins of Form, Architectural Book Publishing Company, Stamford, Connecticut, , pp. 14, 1995.

[14] Whyte, , op. cit., pp. 230-233.

[15] Capra, F., The Web of Life, Anchor Book/Doubleday, New York, London, pp. 21-28, 1996.

[16] Ho, Mae Wan, The Organic Revolution in Science and Implications for Science and Spirituality, Institute of Science in Society, www.isis.org.uk/future.php

[17] Capra, F., The Tao of Physics, Flamingo/Fontana Paperbacks, London, pp. 126, 1983.

[18] Bohm, op. cit. pp.11.

[19] Bortoft, The Wholeness of Nature, Lindisfarne Press, Hudson, New York, pp. 12, 1996.

[20] Brady, R., Form and Cause in Goethe's Morphology (part III), Goethe and the Sciences: A Reappraisal, eds. F. Amrine, F. J. Zucker \& H. Wheeler, D. Reidel Publishing Company, Dordrecht, Boston, Lancaster \& Tokyo, pp. $287,1987$.

[21] Ibid. pp. 278

[22] Wahl, D. Zarte Empirie: Goethean Science as a Way of Knowing, www.janushead.org/8-1/Wahl.pdf.

[23] Hoffmann, N., Goethe's Science of Living Form, Adonis Press, Hillsdale, New York, 2007.

[24] Holdrege, C., Seeing the Animal Whole (Chapter 9), Goethe's Way of Science, eds. D. Seamon and A. Zajonc, State University of New York Press, New York, pp. 213-232, 1988.

[25] Colquhoun, M. and A. Ewald, New Eyes for Plants, Hawthorne Press, Stroud, UK, 1996.

[26] Zajonc, A., Goethe and the Science of His Time (Chapter 1), Goethe's Way of Science, eds. D. Seamon and A. Zajonc, State University of New York Press, New York, pp. 26, 1988.

[27] Bortoft, H., The Wholeness of Nature, Lindisfarne Press, Hudson, New York, pp. 62, 1988.

[28] Ibid., pp. 63

[29] Ibid., pp. 64

[30] Ibid., pp. 66

[31] Benyus, J., Biomimicry, Quill/William Morrow, New York, pp. X2, 1997.

[32] Ibid., pp. 4

[33] Todd, N. and J. Todd, From Eco-Cities to Living Machines, North Atlantic Books, Berkeley, California, 1994. 